\title{
Les interventions du pape Benoît XV auprès de Woodrow Wilson pendant la Grande Guerre
}

Marie Gayte

\section{OpenEdition}

\section{Journals}

Édition électronique

URL : https://journals.openedition.org/ideas/1863

DOI : $10.4000 /$ ideas. 1863

ISSN : 1950-5701

Éditeur

Institut des Amériques

Référence électronique

Marie Gayte, «Les interventions du pape Benoît XV auprès de Woodrow Wilson pendant la Grande Guerre », IdeAs [En ligne], 9 | 2017, mis en ligne le 12 juillet 2017, consulté le 18 octobre 2022. URL: http://journals.openedition.org/ideas/1863 ; DOI : https://doi.org/10.4000/ideas.1863

Ce document a été généré automatiquement le 18 octobre 2022.

\section{(c) (i) $\odot$}

Creative Commons - Attribution - Pas d'Utilisation Commerciale - Pas de Modification 4.0 International - CC BY-NC-ND 4.0

https://creativecommons.org/licenses/by-nc-nd/4.0/ 


\title{
Les interventions du pape Benoît XV auprès de Woodrow Wilson pendant la Grande Guerre
}

\author{
Marie Gayte
}

1 Dès son intronisation le 6 septembre 1914, le pape Benoît XV se tourna vers les ÉtatsUnis, grande puissance neutre grâce à laquelle il espérait faire aboutir ses objectifs de paix. Depuis le début du conflit, Saint-Siège et Washington avaient lancé tour à tour des appels à la paix, et leurs positions semblaient proches. Fort de ce constat, le pape déploya beaucoup d'efforts pendant tout le conflit dans l'espoir de convaincre les ÉtatsUnis, mais ces derniers ne répondirent jamais vraiment à son attente (Latour F., 2001 : 81-83).

D'entrée de jeu, de nombreux éléments auguraient mal de leur accueil à Washington. En 1870, le Saint-Siège avait perdu toute assise territoriale, devenant une autorité dont la légitimité reposait uniquement sur sa puissance spirituelle. Cette légitimité purement morale et désintéressée pourrait lui permettre de jouer un rôle de médiation dans le conflit, mais pour l'instant, la perte de territoire signifiait surtout l'absence de puissance sur laquelle asseoir sa neutralité, et sa légitimité même à intervenir dans la sphère diplomatique était remise en cause (Levillain P., $1987: 126)$. En outre, la diplomatie vaticane reposait presque exclusivement sur une autorité morale résultant du rôle du pape comme chef de l'Église catholique, facteur peu susceptible de peser pour une nation protestante comme les États-Unis. Depuis 1867, le Vatican et Washington n'entretenaient d'ailleurs plus de relations diplomatiques, celles-ci ayant été interrompues sous l'effet d'un fort sentiment anticatholique et face à la perspective imminente de création d'un État italien unifié.

3 Le Vatican disposait depuis de deux canaux pour faire passer ses messages auprès des autorités américaines. Le premier était le délégué apostolique, représentant du SaintSiège auprès de l'épiscopat américain, mais qui ne jouissait pas du statut de diplomate et devait faire preuve de prudence dans ses contacts avec la Maison-Blanche, de crainte de s'attirer l'ire de la presse, assez fortement irriguée de sentiments anticatholiques 
(Castagna L., 2014 :30). Le dialogue s'effectuait également par le biais du cardinalarchevêque de Baltimore, James Gibbons, primat officieux de l'Église américaine, dont la personnalité même obérait les chances du Vatican de convaincre la Maison-Blanche. Mgr Gibbons était extrêmement sensible à la virulence du sentiment anticatholique aux États-Unis, sentiment qui résultait souvent de la méfiance des Américains envers un groupe soupçonné de privilégier son allégeance au pape au détriment de celle due au président. Il se montra donc réticent à transmettre auprès de ce dernier certaines requêtes émanant du Saint-Siège, les jugeant dommageables pour la réputation de ses ouailles. Il fit aussi montre d'un patriotisme exacerbé et d'un soutien inconditionnel à la politique étrangère de son pays, même si celle-ci était diamétralement opposée aux désirs de Benoît XV. Il apporta ainsi son soutien à la campagne de préparation militaire de Wilson ainsi qu'à l'établissement d'un service militaire universel (une décision condamnée par Benoît XV), et donna, avec les autres membres de l'épiscopat, des gages de soutien indéfectible une fois l'entrée en guerre des États-Unis actée. Le 18 avril 1917, les archevêques envoyèrent ainsi un "serment " au président Wilson, se disant émus «au plus profond de leur cœur par l'appel vibrant » de ce dernier, et acceptant " pleinement et sans réserve » la déclaration de guerre, se disant prêts à coopérer « de toutes les manières possibles avec notre président et notre gouvernement national afin que la sainte et grande cause de la liberté triomphe, et que notre pays bien-aimé sorte de cette épreuve plus fort et plus noble que jamais » (Griffin M., 2007 :5). En outre, en novembre 1917, les évêques américains mirent en place un National Catholic War Council, organe visant à organiser l'effort de guerre des catholiques américains, dont la formation est décidée en août, moment choisi par le pontife pour envoyer une note de paix aux nations belligérantes.

4 Mgr Gibbons présentait un autre inconvénient en tant qu'émissaire auprès de la Maison-Blanche : il déplaisait fortement à Wilson, qui ne supportait pas que le prélat livre à la presse les détails de ses entrevues à la Maison-Blanche. Le peu de sympathie de Wilson pour Gibbons s'expliquait aussi surtout par l'assez fort anticatholicisme du président américain, majoré par son mépris des immigrants italiens et d'Europe de l'Est, comme en témoignèrent ses écrits d'historien.

5 En outre, Wilson n'accordait que peu de crédit aux initiatives du pape, qu'il estimait avant tout motivées par un penchant pour l'Autriche-Hongrie, dernière grande puissance catholique et rempart contre l'orthodoxie russe dont il redoutait la désintégration, et dont il pouvait espérer récupérer, en cas de victoire, une assise territoriale (Fogarty G., 1985 : 209-210)ํㅣㄹ. De plus, pendant toute la guerre, Wilson perçut les tentatives de médiation du pape comme une concurrence. Celui à qui l'on a parfois attribué le sobriquet de "croisé de la Maison-Blanche » se sentait investi d'une mission morale et n'était prêt à partager cette mission avec personne.

6 Les tentatives de dialogue avec les États-Unis émanant du Saint-Siège connurent deux phases. Tant que Washington conserva son statut de puissance neutre, le Saint-Siège chercha à l'associer à ses tentatives de médiation ou à encourager celles de Washington, tout en tentant d'empêcher son entrée en guerre. Le Saint-Siège déploya de nombreux gestes de bonne volonté comme quand, en avril 1915, le pape donna une interview à un quotidien américain, dans lequel il saluait les États-Unis, puissance « juste, impartiale, neutre », dont « beaucoup dépend », tout en s'engageant à soutenir Wilson quand celui-ci ferait une "démarche en vue de la paix » (Chiron Y., 2014). Le secrétaire d'État du Saint-Siège, Mgr Gasparri, envoya Mgr Gibbons défendre l'idée 
d'une médiation de paix commune avec les États-Unis le 2 septembre 1915, initiative qui ne rencontra aucun succès. Fin 1916, ce fut l'Autriche-Hongrie qui fit une offre de paix, à la suite de laquelle Mgr Gasparri invita le délégué apostolique Mgr Bonzano à exhorter les Américains à négocier avec les empires centraux. C'est donc avec beaucoup de soulagement que le pape apprit que Wilson proposait ce même mois de décembre une conférence de paix au nom des puissances neutres. Mgr Bonzano fut invité par Mgr Gasparri à encourager cette initiative, l'osservatore Romano publiant le 24 décembre un éditorial laudatif à son sujet, tandis que le Saint-Siège chercha à exercer des pressions sur Guillaume II pour qu'il se montre disposé à négocier.

7 Le Vatican déploya de plus des efforts considérables pour éviter l'entrée en guerre de Washington, de peur de voir la seule puissance neutre capable à ses yeux entrainée dans le conflit. Le pape savait que le danger venait de la guerre sous-marine de l'Allemagne contre les alliés et neutres. En 1915, après le naufrage du Lusitania et de l'Arabic, avec à leur bord de nombreux passagers américains, le Saint-Siège envoya une dépêche à l'Allemagne lui demandant de fournir des explications aux Américains. En août, conformément aux instructions de Gasparri, Gibbons informa Wilson des assurances données par l'Allemagne qu'elle ne coulerait pas d'autre navire sans avertissement. En mai 1916 à nouveau, Mgr Gasparri demanda à Bonzano d'exhorter Wilson à ne rien décider concernant les offensives sous-marines de l'Allemagne, arguant de la possibilité d'un règlement pacifique. Au printemps 1917, le Saint-Siège renouvellera ses appels pour éviter l'entrée des États-Unis dans le conflit, en vain.

8 L'entrée en guerre de l'Amérique aux côtés de la Triple-Entente en avril 1917 constitua un sérieux revers pour le Saint-Siège. Son silence assourdissant entre mars et juillet 1917 au sujet de la participation américaine contraste avec les manifestations de patriotisme de ses évêques. Pour autant, l'entrée en guerre ne signifia pas la fin des tentatives de rapprochement avec les États-Unis, associés et non pas alliés de l'Entente, qui continuaient de prôner une paix sans victoire, ce qui séduisait le Vatican. C'est ainsi que le Saint-Siège plaçait beaucoup d'espoir dans un accueil favorable de Washington quand il envoya à tous les belligérants sa Note de paix le $1^{\mathrm{er}}$ août 1917 , dans laquelle il les exhortait à reconnaître la primauté du droit, à désarmer, à accepter un arbitrage international, à restituer les territoires occupés et à renoncer aux réparations. Washington, comme les autres belligérants, fit mauvais accueil à la note, le secrétaire d'État, Robert Lansing, écrivant à Wilson que « l'énonciation des termes de paix émane de l'Autriche-Hongrie et qu'ils ont probablement été approuvés par le gouvernement allemand » et qualifiant le pape, "probablement involontairement ou par compassion pour l'Autriche-Hongrie [d'] agent de l'Allemagne». En outre, la note était assez malvenue pour Wilson alors que Washington cherchait à juguler le mouvement pacifiste et à motiver l'opinion. Mgr Gasparri contacta Mgr Gibbons pour lui demander d'évoquer la Note de paix auprès de Wilson, ce à quoi le cardinal de Baltimore s'engagea. Pour autant, Gibbons ne sollicita jamais l'entrevue promise auprès du président, expliquant au secrétaire d'État Mgr Gasparri que « le moment présent est particulièrement délicat pour les intérêts de la religion et malheureusement les critiques hostiles ne sont pas des moindres " (Renoton-Beine N., 2004 : 292).

9 Après l'échec de sa Note de paix, le Saint-Siège consacra le reste de la guerre à essayer d'obtenir des États-Unis une place à la future conférence de paix, dont il avait été exclu par l'article XV du Traité de Londres. Dès que le Saint-Siège apprit l'existence de cette clause secrète, en janvier 1916, il chercha à mobiliser le délégué apostolique, 
l'exhortant à susciter une campagne dans la presse catholique pour inciter à l'action l'Administration Wilson, initiative qui n'eut une fois de plus pas l'effet escompté. Pour chercher à impliquer Wilson, le Saint-Siège monta un véritable front international en 1918, impliquant les Britanniques et le cardinal belge Mercier par le biais de la délégation apostolique à Washington. Pour autant, Gibbons refusa les requêtes de Gasparri de rencontrer Wilson pour évoquer le sujet. Si le secrétaire d'État formulait sa conviction qu'une intervention du président Wilson "résoudrait tout ", Gibbons refusait de voir l'Église américaine entraînée dans une mission vaine surtout susceptible à ses yeux d'accroître les préjugés anticatholiques.

Benoît XV lança une ultime tentative de médiation, en octobre 1918, alors que la défaite de l'Allemagne était imminente, Gasparri dépêchant Mgr Gibbons pour évoquer avec Wilson une demande d'armistice austro-hongroise, tout en envoyant un appel à la paix au président américain de la part du pape. Gibbons refusa là encore de s'acquitter de cette mission, inopportune et susceptible de «mettre le président en colère ». La réponse de la Maison-Blanche aux missives en provenance de Rome fut évasive et ne satisfit en rien les attentes du souverain pontife. En novembre 1918, les vœux de réussite de Benoît XV à Wilson pour son action pacifique restèrent sans réponse.

11 Apprenant que le président avait prévu de se rendre en Europe avant la conférence de paix, le Saint-Siège l'informa que le pape souhaitait le recevoir en audience, sans doute motivé par la possibilité d'évoquer sa participation à la conférence de paix. Malgré la réticence initiale de Wilson, le 9 janvier 1919 se tint la première audience entre un souverain pontife et un président américain, mais rien dans les documents d'archives ne donne à penser que la rencontre, qui dura à peine vingt minutes, ait donné lieu à autre chose qu'un échange de banalités.

Quelles qu'aient été les motivations du Vatican, à aucun moment le président Wilson ne souhaita accorder de crédit à ses initiatives de paix. Pour autant, le fait que le SaintSiège soit exclu des négociations et qu'il reste dépourvu d'assise territoriale n'empêcha pas son retour sur la scène internationale, bien au contraire. Entre la fin de la guerre et celle du pontificat de Benoît XV, dix nonciatures furent établies ou rouvertes. Il faudra attendre le début de la Deuxième Guerre mondiale pour que les États-Unis décident de l'opportunité d'un rapprochement avec le Saint-Siège, et ce sera cette fois-ci de Washington qu'émanera la demande, vite acceptée, d'un partenariat en faveur de la paix et des réfugiés.

\section{BIBLIOGRAPHIE}

\section{Références}

Castagna, Luca, A Bridge Across the Ocean : The United States and the Holy See between the Two World Wars, Washington D.C., Catholic University of America, 2014.

Chiron, Yves, Benoît XV, le pape de la paix, Paris, Perrin, 2014. 
Fogarty, Gerald, The Vatican and the American Hierarchy from 1870 to 1965, Collegeville, Minn., Michael Glazier, 1985.

Griffin, Mike, «Snubbed : Pope Benedict XV and Cardinal James Gibbons », The Sign of Peace: Journal of the Catholic Peace Fellowship, vol. $6 n^{\circ} 1$, 2007, http://www.catholicpeacefellowship.org/ downloads/BenedictXV_Gibbons.pdf

Latour, Francis, « Le Saint-Siège et les États-Unis à la recherche de la paix pendant la première guerre mondiale : la collaboration impossible », Guerres mondiales et conflits contemporains, ${ }^{\circ} 199$, juillet 2001.

Levillain, Philippe, «Le Saint-Siège et la Première Guerre mondiale », in Les Internationales et le problème de la guerre au XXe siècle. Actes du colloque de Rome, Rome, École Française de Rome, 1987.

Pollard, John, The Unknown Pope : Benedict XV (1914-1922) and the Pursuit of Peace, London, Geoffrey Chapman, 1999.

Renoton-Beine, Nathalie, La Colombe et les Tranchées, Paris, Cerf, 2004.

\section{NOTES}

1. Si des penchants pro-autrichiens ont pu se manifester, l'historiographie semble avoir tranché une fois pour toute la question des motivations de l'intervention de Benoît XV, qui seraient avant toutes celles d'un pape impartial et profondément ébranlé par les horreurs de cette guerre d'un nouveau genre, véritable « suicide » de l'Europe « civilisée » (Pollard, p. 150). Voir à cette fin Latour, p. 12, et Nathalie RenotonBeine, La Colombe et les Tranchées, Paris, Cerf, 2004, p. 68. Seule exception à cette tendance, les travaux d'Annie Lacroix-Riz, « Le Vatican et les buts de guerre germaniques de 1914 à 1918 ", Revue d'histoire moderne et contemporaine, vol. 42, n 4, octobre-décembre 1995, p. 517-555.

\section{AUTEUR}

\section{MARIE GAYTE}

Maître de conférence à l'UFR Lettres et chercheuse au laboratoire Babel de l'Université de Toulon, Marie Gayte est spécialiste de la politique américaine contemporaine. Auteur d'une thèse sur les États-Unis et le Vatican, ses travaux l'ont notamment conduite à étudier de près les liens étroits tissés entre religion et politique. 